\title{
The phenomenon of magnetic exchange bias in ferromagnetic nanocomposites grown by electron beam evaporation
}

\author{
M.V. Radchenko ${ }^{1^{*}}$, G.V. Lashkarev ${ }^{1}$, M.E. Bugaiova ${ }^{1}$, O.E. Baibara ${ }^{1}$, W. Knoff ${ }^{2}$, T. Story ${ }^{2}$, L.A. Krushynskaya ${ }^{3}$, \\ Y.A. Stelmakh ${ }^{3}$, Y. Dumond ${ }^{4}$ \\ ${ }^{1}$ I.M. Frantsevych Institute for Problems of Material Science, National Academy of Sciences of Ukraine, \\ 3, Krzhizhanovskogo str., Kyiv, Ukraine \\ ${ }^{2}$ Institute of Physics, Polish Academy of Sciences, Al. Lotnikow 32/46, Warsaw, Poland \\ ${ }^{3}$ E.O. Paton Electric Welding Institute, Academy of Sciences of Ukraine, 68, Antonovich str., Kyiv, Ukraine \\ ${ }^{4}$ Laboratoire GEMaC, University of Versailles St Quentin en Yvelines, Versailles, France \\ ${ }^{*}$ E-mail: radch@isp.kiev.ua
}

\begin{abstract}
For the first time, in ferromagnetic nanocomposites $\mathrm{Co} / \mathrm{CoO} / \mathrm{Al}_{2} \mathrm{O}_{3}$ formed by two-crucible electron beam evaporation with deposition on a policor substrate, the magnetic exchange bias was observed. It is associated with the magnetic interaction of the ferromagnetic metal core of Co nanoparticles with antiferromagnetic $\mathrm{CoO}$ layer on their surface. The low value of magnetic exchange bias is attributed to the small thickness of the $\mathrm{CoO}$ shell, inasmuch as the energy of exchange magnetic anisotropy, which decreases with diminishing the antiferromagnetic $\mathrm{CoO}$ layer thickness, cannot provide a significant increase of the coercive force when changing the magnetic field direction. The ferromagnetic nanocomposites with the magnetic exchange bias can be used as a bias magnetic layer for magnetoresistive sensors.
\end{abstract}

Keywords: nanocomposites, ferromagnetic nanoparticles, magnetic exchange bias, electron beam deposition.

doi: https://doi.org/10.15407/spqeo21.02.125

PACS 75.30.Et, 75.50.Cc, 75.75.Fk

Manuscript received 25.05.18; revised version received 12.06.2018; accepted for publication 27.06.18; published online 03.07.18.

\section{Introduction}

The phenomenon of magnetic exchange bias (MEB is the shift of the hysteresis loop along the axis of magnetic field) observed in ferromagnetic (FM) - antiferromagnetic (AFM) structures. It occurs in systems where the Curie temperature of ferromagnetic exceeds the Neel temperature of antiferromagnetic. The effect was firstly discovered in 1956 year by Meiklejohn and Bean in the film structure $\mathrm{Co} / \mathrm{CoO}$ [1]. Opposite to metalic cobalt, which is FM with Curie temperature $T_{\mathrm{C}}=1394^{\circ} \mathrm{K}, \mathrm{CoO}$ reveals AFM properties with Neel temperature $T_{\mathrm{N}}=290 \mathrm{~K}$.

The shift is observed after cooling the system in an external magnetic field on the initial temperature $T_{\mathrm{N}}<T<T_{\mathrm{C}}$ to $T<T_{\mathrm{N}}$. The MEB nature relates to the magnetic exchange interaction between the magnetic moments $(\mathrm{M})$ of $\mathrm{Co}$ and $\mathrm{CoO}$ at their interface.

The AFM layer prevents rotation of the FM Co magnetic moment at the interface $\mathrm{Co} / \mathrm{CoO}$. Back reorientation of the $\mathrm{Co}$ magnetic moment in these structures needs a larger magnetic field at its opposite direction as compared with a situation when Co NP's are not covered by $\mathrm{CoO}$ AFM layer.

Thus, the exchange energy at the interface grows, and giant magnetic anisotropy $E_{a}=-k_{a} \cos \theta$ appears $(\theta$ is the angle between orientation of the Co magnetic moments to the interface (in the nearest AFM layer) and magnetic field $H$ ). The value of anisotropy constant $k_{a}$ reaches $\sim 10^{5} \mathrm{~J} / \mathrm{m}^{3}$ [2]. This leads to a shift of the center of hysteresis loop toward the negative magnetic field (relatively to the direction of the first applied one). This shift is called "magnetic exchange bias" and is defined by the equation:

$$
M E B=\frac{1}{2}\left(H_{c}^{-}+H_{c}^{+}\right),
$$

where $H_{c}^{-}, H_{c}^{+}$are coercivities for the negative and positive directions of magnetic field. 
Table 1. The main technological growth conditions.

\begin{tabular}{|l|c|c|}
\hline Samples set number & 303 & 302 \\
\hline$T_{\text {cond }},{ }^{\circ} \mathrm{C}$ & $80 \ldots 200$ & $80 \ldots 200$ \\
\hline$I_{\mathrm{Al}_{2} \mathrm{O}_{3}}, \mathrm{~A}$ & 0.49 & 0.44 \\
\hline$I_{\mathrm{Co}}, \mathrm{A}$ & 0.34 & 0.34 \\
\hline$\delta, \mu \mathrm{m}$ & $12 \ldots 19.5$ & $4.5 \ldots 8$ \\
\hline$V_{\text {cond }}, \mu \mathrm{m} / \mathrm{min}$ & $2 \ldots 3.2$ & $0.7 \ldots 1.2$ \\
\hline$C_{\mathrm{Co}}$, at. $\%$ & $12.5 \ldots 28.5$ & $35.5 \ldots 53$ \\
\hline
\end{tabular}

Table 2. The characteristics of the studied samples.

\begin{tabular}{|l|c|c|c|}
\hline Sample & $T_{\text {cond }},{ }^{\circ} \mathrm{C}$ & $C_{\text {Co }}$, at. $\%$ & $\delta, \mu \mathrm{m}$ \\
\hline $303-9$ & 80 & 12.27 & 16.8 \\
\hline $303-14$ & 80 & 22.42 & 18.4 \\
\hline $302-22$ & 145 & 42.87 & 7.57 \\
\hline
\end{tabular}

MEB can find applications in magnetoresistive sensors and magnetic memory as a bias magnetic layer. We investigated MEB for ferromagnetic nanocomposites (FMNC) $\mathrm{Co} / \mathrm{CoO} / \mathrm{Al}_{2} \mathrm{O}_{3}$ formed by electron-beam evaporation with condensation on polycore substrate, which demonstrate sufficiently high values of negative tunnel magnetoresistance. Also the electric and thermoelectric properties in the wide range of temperatures $(5 \ldots 300 \mathrm{~K})$ and magnetic fields were studied in our paper [2]. $\mathrm{FMNC} \mathrm{Co} / \mathrm{CoO} / \mathrm{Al}_{2} \mathrm{O}_{3}$ are threephase materials. Ferromagnetic Co nanoparticles (NP) surrounded by $\mathrm{CoO}$ shells are distributed in a dielectric $\mathrm{Al}_{2} \mathrm{O}_{3}$ matrix. It gives the possibility to observe MEB in this system [2, 3].

The main objectives for this work were as follows: 1) to identify MEB at different temperatures $T$ $\left.\left(T_{\mathrm{N}}<T<T_{\mathrm{C}}\right) ; 2\right)$ to research the dependence of MEB on the magnetic field and Co concentration in FMNC.

\section{Experimental details}

Ferromagnetic nanocomposites $\mathrm{Co} / \mathrm{CoO}$ in $\mathrm{Al}_{2} \mathrm{O}_{3}$ matrix were grown using the electron-beam facility. It operates on the basis of two-crucible scheme with simultaneous evaporation and condensation of $\mathrm{Co}$ and $\mathrm{Al}_{2} \mathrm{O}_{3}$ on a planar policore substrate. The main technological parameters for controlling the structure and properties of FMNC condensates are the rates of components evaporation, which are proportional to the currents of the electron beam evaporators $\left(I_{\mathrm{Al}_{2} \mathrm{O}_{3}}, I_{\mathrm{Co}}\right)$ and substrate condensing temperature $\left(T_{\text {cond }}\right)$. The latter influences on (1) the concentration of metalic cobalt $\left(C_{\mathrm{Co}}\right)$, (2) the rate of condensation $V_{\text {cond }}$ of the composite and (3) formation of Co NPs. Co content in FMNC depends on the ratio $I_{\mathrm{Co}} / I_{\mathrm{Al}_{2} \mathrm{O}_{3}}$. Determination of the condensate elemental composition was carried out by $\mathrm{X}$-ray microanalyzer (EDX attachment to the scanning electron microscope CamScan 4D) supplied by the program Inca-2000 for processing results. The main technological parameters and Co content $\left(C_{\mathrm{Co}}\right)$ in the FMNC sets 302 and 303 are shown in Table 1.

Hysteresis loops were measured using the vibrating sample magnetometer (VSM) within the temperature range $5 \ldots 300 \mathrm{~K}$.

\section{Results and discussion}

The hysteresis loops were measured after sample cooling in the magnetic field (FC) of $200 \mathrm{Oe}$ from the temperature $T>T_{\mathrm{N}}$ to the temperature of measurements $\left(T<T_{\mathrm{N}}\right)$. The MEB determination was made on the samples Nos 303-9, 303-14, 302-22. Their main characteristics are summarized in Table 2.

High resolution transmission electron microscopic investigations of the sample No 302-22 with 42.87 at.\% Co were carried out (Fig. 1). The images for FMNC revealed Co NPs in the form of separate inclusions inside the dielectric $\mathrm{Al}_{2} \mathrm{O}_{3}$ matrix (Fig. 1). Dark areas of the bright field image represent Co NPs with the average size $7 \ldots 10 \mathrm{~nm}$. They have a crystalline $\gamma$-Co structure (Fig. 2).

The most clearly pronounced hysteresis loops are shown for the sample 302-22 with 42.87 at.\% Co (see Fig. 3). These loops were measured at three temperatures 5,150 , and $300 \mathrm{~K}$.

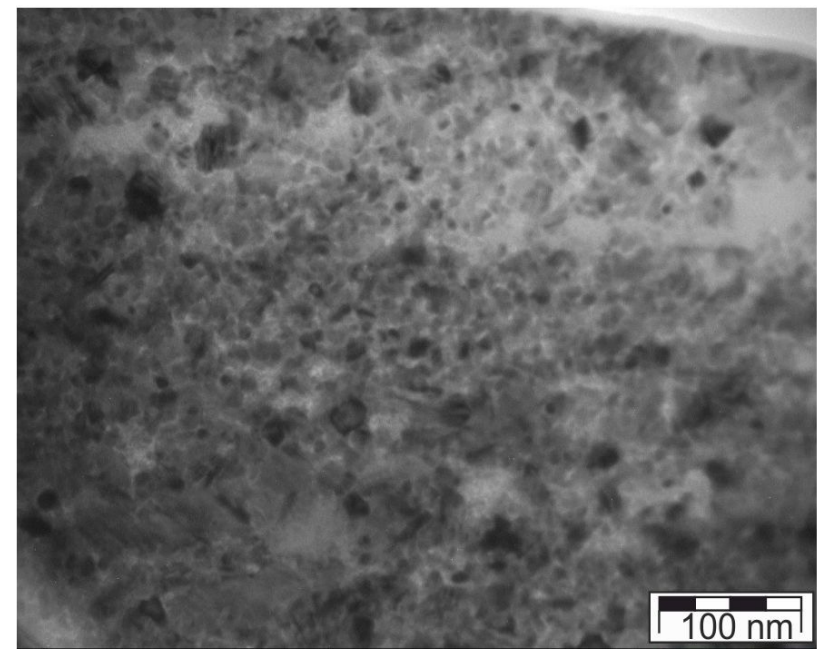

Fig. 1. Transmission electron microscopy bright-field image (scale $100 \mathrm{~nm}$ ) of FMNC sample 302-22 with 42.87 at.\% Co.

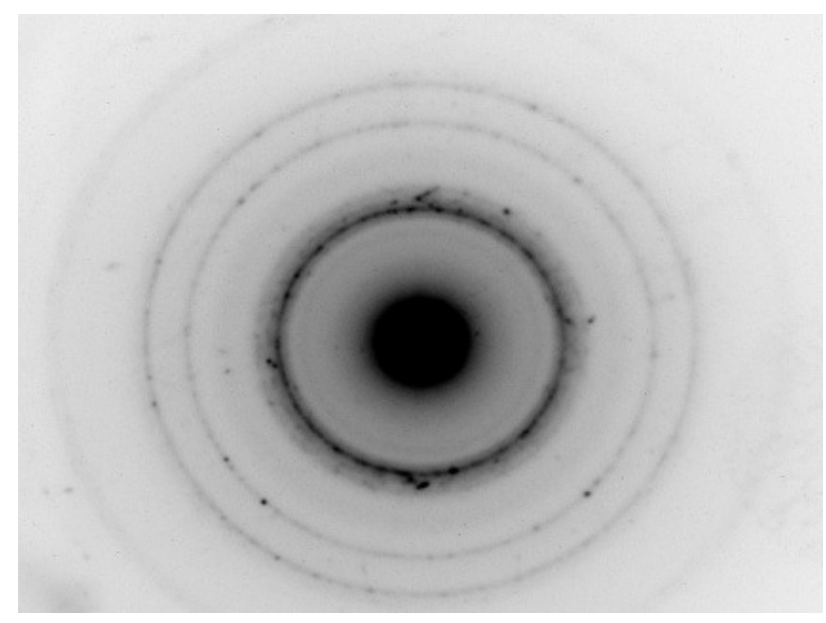

Fig. 2. Electron diffraction pattern of FMNC sample 302-22 with 42.87 at.\% Co. 


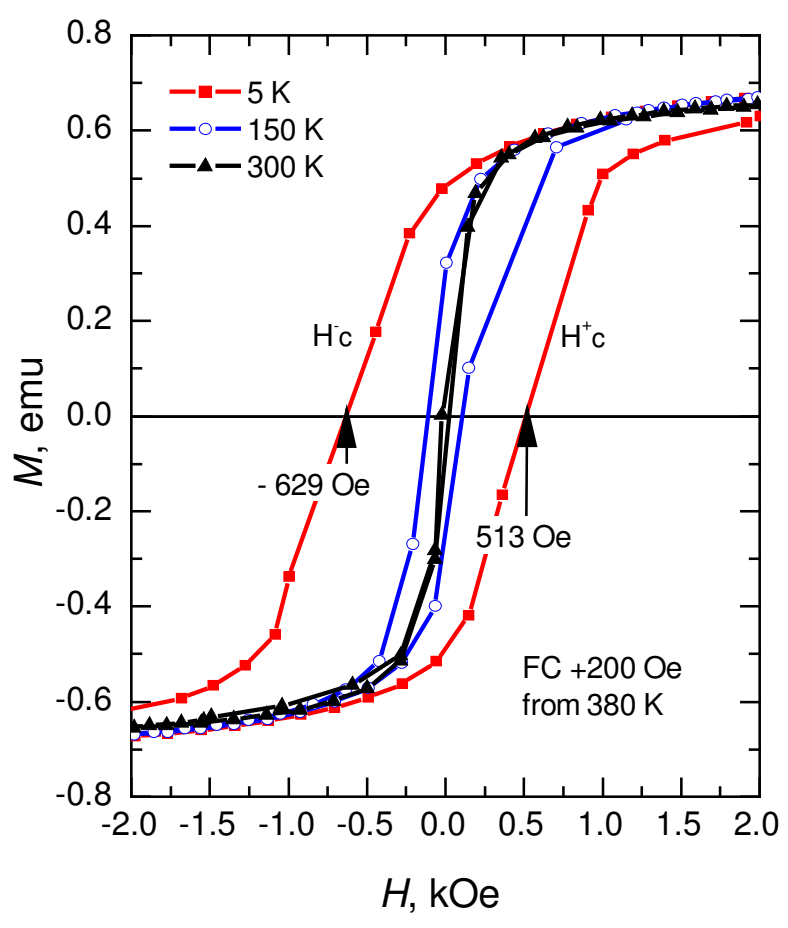

Fig. 3. Hysteresis loops of FMNC sample 302-22 with 42.87 at. \% Co measured at different temperatures.

The coercive field $H_{c}^{-}$decreases from 629 Oe down to 121 and $20 \mathrm{Oe}$ at the temperature increase from 5 up to 150 and $300 \mathrm{~K}$, respectively. The largest shift of the hysteresis loop was observed for measurements at $5 \mathrm{~K}(\mathrm{MEB}=58 \mathrm{Oe})$. It is interesting that at $T=300 \mathrm{~K}$, the hysteresis loop does not disappear. This behavior is associated with the transition from the state of a spin glass at temperatures below the blocking one ( $\left.T_{B}=200 \mathrm{~K}\right)$ [2] to the region of ferromagnetic ordering, obliged to the effect of the magnetostatic interaction between $\mathrm{Co} / \mathrm{CoO} \mathrm{NPs}$. At $T=300 \mathrm{~K}$ instead of the usual superparamagnetic state there is an intermediate region of magnetic ordering for the ensemble of NPs [4].

The MEB dependence on the Co content in FMNC at $T=5 \mathrm{~K}$ for the samples cooled from $380 \mathrm{~K}$ in the magnetic field $H=10 \mathrm{kOe}$ is shown in Fig. 4. MEB growth with an increase of Co content and hence the size of NPs, what agrees with [5], but in our case the magnitude of MEB is two orders lower.

The magnetic exchange bias growth can be explained by the fact that with increasing the fraction of Co in the composite, the size of Co NPs increases [6], and therefore the volume of the AFM $\mathrm{CoO}$ layer enlarges, too. It leads to an increase of magnetic anisotropy, and therefore to an increase of MEB. It is interesting that for a certain value of the magnetic field for FC regime (in our case $200 \mathrm{Oe}$ ) MEB saturates (Fig. 5). It means that the exchange energy of $\mathrm{Co} / \mathrm{CoO}$ NPs in this field reaches its maximum magnitude and the further increase of the magnetic field does not lead to the increase of MEB.

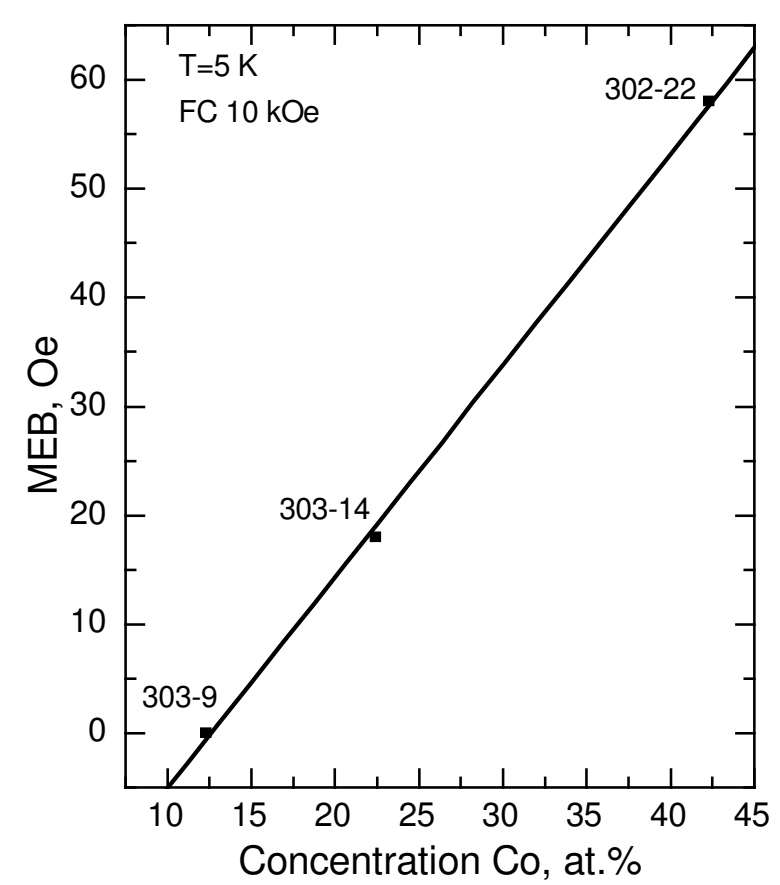

Fig. 4. The dependence of the magnetic exchange bias in FMNC on the Co concentration.

Results of other experimental studies of MEB for core/shell NPs $\mathrm{Co} / \mathrm{CoO}$ in dielectric matrixes carried out in [4-7] are listed in Table 3.

One can suppose that this low MEB magnitude in our case can be caused by the small thickness of $\mathrm{CoO}$ layer. Indeed, accordingly to [8]:

$\mathrm{MEB} \propto J_{F M-A F M} \propto \sqrt{t_{A F M}}$,

where $J_{F M-A F M}$ is the exchange energy at the interface FM/AFM, $t_{\mathrm{AFM}}$ - thickness of AFM layer.

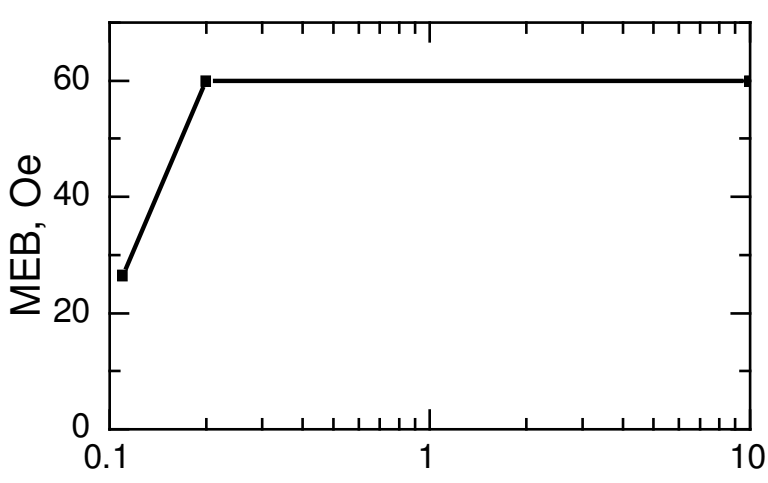

$\mathrm{H}, \mathrm{kOe}$

Fig. 5. The magnetic exchange bias dependence for the $\mathrm{Co} / \mathrm{CoO} / \mathrm{Al}_{2} \mathrm{O}_{3}$ sample $302-22$ on the magnetic field in the $\mathrm{FC}$ regime at $T=5 \mathrm{~K}$. 
Table 3. Parameters of nanoparticles $\mathrm{Co} / \mathrm{CoO}$ in dielectric matrixes.

\begin{tabular}{|l|l|c|c|c|}
\hline The deposition method & FMNC substrate & $\begin{array}{c}\text { Size of } \\
\text { nanoparticles, } \mathrm{nm}\end{array}$ & MEB & References \\
\hline Two-crucibles EB PVD & $\mathrm{Co} / \mathrm{CoO} / \mathrm{Al}_{2} \mathrm{O}_{3}$ & 7 & $0.058 \mathrm{kOe}$ at $5 \mathrm{~K}$ & this research \\
\hline Pulsed laser deposition & $\mathrm{Co} / \mathrm{CoO} / \mathrm{Al}_{2} \mathrm{O}_{3} \mathrm{Si}(111)$ & 2 & $0 \mathrm{kOe}$ at $5 \mathrm{~K}$ & {$[7]$} \\
\hline $\begin{array}{l}\text { Standard reactive } \\
\text { sputtering }\end{array}$ & $\begin{array}{l}\mathrm{Co} / \mathrm{CoO} / \mathrm{Al}_{2} \mathrm{O}_{3} \mathrm{Si}(111) \\
\mathrm{Co} / \mathrm{CoO} \mathrm{Si}(111)\end{array}$ & 5 & $\begin{array}{c}0.05 \mathrm{kOe} \text { at } 5 \mathrm{~K} \\
7.4 \mathrm{kOe} \text { at } 5 \mathrm{~K}\end{array}$ & {$[8]$} \\
\hline Laser-ablated & $\mathrm{Co} / \mathrm{CoO} / \mathrm{ZrO}{ }_{2}$ & $\sim 2$ & $0.9 \mathrm{kOe}$ at $1.8 \mathrm{~K}$ & {$[9]$} \\
\hline Magnetron sputtering & $\mathrm{Co} / \mathrm{CoO} / \mathrm{MgO} \mathrm{Si}(100)$ & 5 & $2.46 \mathrm{kOe}$ at $2 \mathrm{~K}$ & {$[10]$} \\
\hline
\end{tabular}

Besides, a mismatch between lattice periods of NPs and dielectric matrix, as the authors $[8,10]$ noted, results in a significant decrease of the MEB value. Therefore, we have the lowest $\mathrm{MEB}$ value close to $58 \mathrm{Oe}$ for $\mathrm{Al}_{2} \mathrm{O}_{3}$ dielectric matrix (the lattice mismatch for $\mathrm{Co}$ and $\mathrm{Al}_{2} \mathrm{O}_{3}$ is $42.6 \%$, whereas for $\mathrm{MgO}$ it is equal to $1.1 \%$ ).

In the case when the value of MEB increases with the thickness of the AFM CoO shell on Co NP, a lower MEB value in our case of investigated FMNC can be explained by a small thickness of CoO layer.

But there exist another reason for low $\mathrm{MBE}$ magnitude. This reason is a non-perfect structure of $\mathrm{CoO}$ shell: 1) due to its non-homogeneous character (availability of $\mathrm{CoO}$ nano-inclusions in $\mathrm{Co} \mathrm{NPs} \mathrm{Al}_{2} \mathrm{O}_{3}$ matrix surrounding) [8]; 2) due to large stresses generated by great misfit between $\mathrm{Co} / \mathrm{CoO}$ and $\mathrm{Al}_{2} \mathrm{O}_{3}$ matrix [10].

Nevertheless, the same circumstances are actual to other experimental results represented in Table 3. FMNC samples were grown by authors [7-10] in more nonequillibrium conditions than in our case of electron beam evaporation. But those conditions did not lead to lower values of MBE. Therefore, we suppose that in our case conditions of FMNC layer growth during electron beam evaporation of constituents could not lead to nonhomogeneous $\mathrm{Co} / \mathrm{CoO}$ distribution in $\mathrm{Al}_{2} \mathrm{O}_{3}$ and to stresses in $\mathrm{Co} / \mathrm{CoO}$.

\section{Conclusions}

FMNCs containing Co within the concentration range $12 . .53$ at.\% were grown by two-crucible electron beam evaporation with deposition on the policor substrates. Firstly, the "magnetic exchange bias" was observed in nanocomposites $\mathrm{Co} / \mathrm{CoO} / \mathrm{Al}_{2} \mathrm{O}_{3}$ grown by the above mentioned method. This bias is associated with the magnetic exchange interaction between the ferromagnetic Co metallic cores and AFM CoO layers on the surface of Co NPs. The small magnetic shift (58 Oe) in FMNCs $\mathrm{Co} / \mathrm{CoO} / \mathrm{Al}_{2} \mathrm{O}_{3}$ is significantly lower than in the case of Co NPs treated in oxygen at the high temperature $\sim 1000{ }^{\circ} \mathrm{C}$, accordingly to literature data $(-9.5 \mathrm{kOe})$. It can be explained by lowering the energy of the exchange magnetic anisotropy, which decreases with the thickness of antiferromagnetic layer $\mathrm{CoO}$ and leads to small MEBs.

\section{References}

1. Meiklejohn W.H., Bean C.P. New Magnetic Anisotropy. Phys. Rev. 102. 1956. P. 1413-1414.

2. Radchenko M.V., Lashkarev G.V., Bugaiova M.E. et al. Magnetic and electrical properties of ferromagnetic nano-composites based on $\mathrm{Co}$ nanoparticles in $\mathrm{Al}_{2} \mathrm{O}_{3}$ matrix. phys. status solidi (b). 2011. 248. P. 1619-1622.

3. Loosveet H. Exchange Bias in $\mathrm{Co} / \mathrm{CoO}$ Bilayers and the Influence of Lateral Conferment. EPublishing Inc., Katholieke Universiteit Leuven, 2005.

4. Krichevtsov B.B., Gastev S.V., Ilyushchenko D.S. et al. Magnetic properties of the arrays of cobalt nanoparticles on the surface of $\mathrm{CaF}_{2}(110) / \mathrm{Si}(001)$. Physics of the Solid State. 2009. 51. P. 109-117.

5. Gangopadhyay S., Hadjipanayis G.C., Sorensen C.M., and Klabunde K.J. Exchange anisotropy in oxide passivated Co fine particles. J. Appl. Phys. 1993. 73. P. 6964.

6. Radchenko M.V., Lashkarev G.V., Bugaiova M.E. et al. The features of magnetic and thermoelectric properties of ferromagnetic nanocomposites of different composition. 41-st "Jaszowiec" International School \& Conference on the Physics of Semiconductors. Krynica-Zdrój, Poland, June 8 June 15, 2012. P. 82.

7. Dobrynin A.N., Temst K., Lievens P. et al. Observation of $\mathrm{Co} / \mathrm{CoO}$ nano-particles below the critical size for exchange bias. J. Appl. Phys. 2007. 101. P. 113913-113918.

8. Nogues J., Sort J., Langlais V. et al. Exchange bias in nanostructures. Phys. Repts. 2005. 422. P. 65117.

9. Kovylina M., del Muro M. Garcia et al. Controlling exchange bias in $\mathrm{Co}-\mathrm{CoO}_{\mathrm{x}}$ nanoparticles by oxygen content. Nanotechnology. 2009. 20. P. 1-12.

10. Ge C.N., Xiangang Wan et al. Giant Exchange Bias and Ferromagnetism in the $\mathrm{CoO}$ Shell of $\mathrm{Co} / \mathrm{CoO}$ $\mathrm{MgO}$ Core-Shell Nanoparticles. Nanjing University, 2009. P. 1-14. 


\section{Authors and CV}

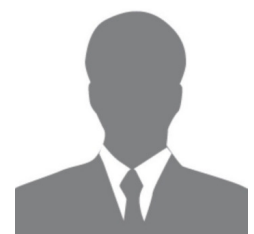

Radchenko Mikhail Vasilevich, $\mathrm{PhD}$ of Physics and Mathematics at the Institute for Problems in Materials Science. The head of research direction of ferromagnetic nanocomposites. The area of his scientific interests includes physics of semiconductors and dielectrics, ferromagnetic nanocomposites, magnetically dissolved semiconductors.

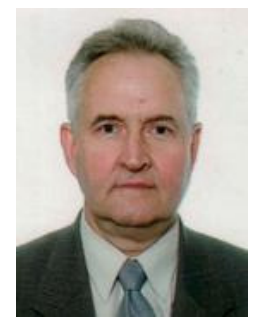

Lashkarev Georgii Vadimovich, born in 1937, defended his Doctoral Dissertation in physics of semiconductors and dielectrics in 1981 and became full professor in 1988. Professor at the department "Physics and technology of photovoltaic and magnetoactive materials" at the Institute for Problems in Materials Science. Authored over 640 publications. The area of his scientific interests includes functional electronics materials, ferromagnetic nanocomposites, magnetic, electrical and optical phenomena in zinc oxide, narrowband and layered semiconductors, ferromagnetism of magnetically dissolved semiconductors.

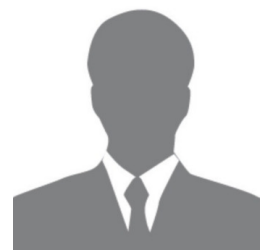

Baibara Oleksii Evgenovich born in 1992, postgraduate student at the Institute for Problems in Materials Science since 2015. The area of his scientific interests is ferromagnetic nanocomposites, disordered systems and granular amorphous composites.

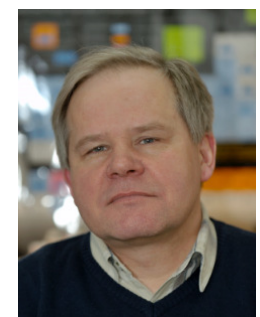

Tomasz Story is the professor http://www.ifpan.edu.pl/ON-

1/on1.2/index.php?1=en\&p=staf $\& n=1$ and head of Department "Physics of semiconductors" at the Institute of Physics, Polish Academy of Sciences, Warsaw, Poland. The area of his scientific interests includes magnetic, electrical and optical phenomena in layered semiconductors, ferromagnetic semiconductors.

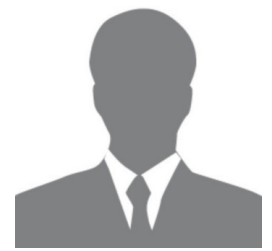

Stelmakh Yaroslav Anatoliyovich is $\mathrm{PhD}$ in the field of Material Science in E.O. Paton Electric welding Institute. The area of his scientific interests includes electron-beam physical vapor deposition, layered systems, nanocomposites.

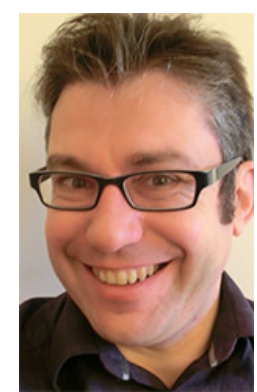

Yves Dumont is the leading professor at the Université de Versailles SaintQuentin en Yvelines, Versailles, France. The area of his scientific interests: thin films nanotechnology, condensed matter physics, semiconductor spintronics, pulsed laser deposition. 